\title{
Article \\ Change in Shoulder Function in the Early Recovery Phase after Breast Cancer Surgery: A Prospective Observational Study
}

\author{
Jihee Min ${ }^{1,2,+}$, Jee Ye Kim ${ }^{3,+}$, Sujin Yeon ${ }^{1}$, Jiin Ryu ${ }^{2}$, Jin Joo Min ${ }^{2}$, Seho Park ${ }^{3} \mathbb{D}$, Seung Il Kim ${ }^{3} \mathbb{D}$ \\ and Justin Y. Jeon $2,4,5, *$ (D)
}

check for

updates

Citation: Min, J.; Kim, J.Y.; Yeon, S.; Ryu, J.; Min, J.J.; Park, S.; Kim, S.I.; Jeon, J.Y. Change in Shoulder Function in the Early Recovery Phase after Breast Cancer Surgery: A Prospective Observational Study. J. Clin. Med. 2021, 10, 3416. https:// doi.org/10.3390/jcm10153416

Academic Editors: Rossana Berardi and Emmanuel Andrès

Received: 27 June 2021

Accepted: 28 July 2021

Published: 31 July 2021

Publisher's Note: MDPI stays neutral with regard to jurisdictional claims in published maps and institutional affiliations.

Copyright: (c) 2021 by the authors. Licensee MDPI, Basel, Switzerland. This article is an open access article distributed under the terms and conditions of the Creative Commons Attribution (CC BY) license (https:// creativecommons.org/licenses/by/ $4.0 /)$.
1 Department of Physiology, Yonsei Institute of Sports Science \& Exercise Medicine, Yonsei University Wonju College of Medicine, Wonju 26426, Korea; jihee8700@yonsei.ac.kr (J.M.); seuyeonn@naver.com (S.Y.)

2 Exercise Medicine and Rehabilitation Laboratory, Department of Sport Industry Studies, Yonsei University, Seoul 03722, Korea; wldls82@yuhs.ac (J.R.); wlswn09155@gmail.com (J.J.M.)

3 Division of Breast Surgery, Department of Surgery, Yonsei University College of Medicine, Seoul 03722, Korea; JEEYE0531@yuhs.ac (J.Y.K.); PSH1025@yuhs.ac (S.P.); SKIM@yuhs.ac (S.I.K.)

4 Exercise Medicine Center for Diabetes and Cancer Patients, Yonsei University, Seoul 03722, Korea

5 Cancer Prevention Center, Yonsei Cancer Center, Shinchon Severance Hospital, Seoul 03722, Korea

* Correspondence: jjeon@yonsei.ac.kr or skim@yuhs.ac

+ These authors equally contributed to this work.

\begin{abstract}
Breast cancer surgery significantly affects the shoulder's range of motion (ROM) and strength. However, the extent of shoulder impairment, as well as patterns of recovery immediately after surgery, is not fully understood. Therefore, we aimed to investigate shoulder ROM and strength during the early recovery phase after surgery. Thirty-two breast cancer patients were observed five times: the day before surgery, discharge day (postoperative day 1 (POD1) or (POD2)), first outpatient visit (POD7-10), second outpatient visit (POD14-20), and third outpatient visit (POD21-30). We assessed shoulder passive ROM and strength for both affected and unaffected arms at each observation. ROM decreased in both affected and unaffected sides post-surgery. ROM on the affected side did not recover to the pre-surgery level until the third outpatient visit (POD24). In contrast, the ROM on the unaffected side recovered to the pre-surgery level by the first outpatient visit (POD10). The shoulder strength of both arms declined and did not recover to pre-surgery levels. Shoulder strength in the affected arm significantly decreased immediately after surgery (52.9\% of the pre-surgery levels) and did not recover until the third outpatient visit (62.5\% of the pre-surgery levels), whereas that in the unaffected arm decreased gradually $(83.1 \pm 2.3$ at POD 1 and $78.9 \pm 2.9$ at POD 24). Descriptively, patterns of recovery in ROM may vary according to types of surgery while patterns of recovery in shoulder strength did not: shoulder strength significantly decreased and did not recover notably regardless of types of surgery. Both shoulder ROM and strength reduced during the early recovery phase after breast cancer surgery regardless of types of surgery, although the degree of reduction was greater in shoulder strength than ROM. Our findings suggest that rehabilitation exercises should be implemented in both upper limbs.
\end{abstract}

Keywords: breast cancer; mastectomy; breast-conserving surgery; range of motion; strength

\section{Introduction}

A surgical approach is the primary step of breast cancer treatment, which aims to completely remove the entire tumor [1]. Even though surgical techniques have improved significantly, breast cancer patients still experience adverse effects, including reduced shoulder range of motion (ROM), impaired upper body strength, chronic pain, and sensory disturbances [2-4].

One of the most common complications after breast cancer surgery is a functional limitation of the upper body. Up to $67 \%$ of breast cancer patients experience arm or shoulder impairment, including pain, numbness, loss of strength, and reduced ROM, after 
surgery [2,5]. Although most breast cancer patients experience some degree of discomfort and functional limitation, the degree of morbidities after breast cancer surgery varies according to surgical methods. Patients undergoing a mastectomy experience 5.7 times (odds ratio (OR) 5.7, 95\% confidence interval (CI) 1.03-31.2) greater postoperative shoulder problems than patients undergoing breast-conserving surgery [5]. Axillary dissection also significantly contributes to the reduction in arm mobility compared with sentinel lymph node biopsy (SLNB) [6]. Regardless of the surgical method, most breast cancer patients experience chronic arm or shoulder discomfort, which lasts up to 3 years after surgery [5].

Shoulder problems in breast cancer patients affect their daily activities, such as pulling a sweater overhead, fastening a bra, zipping up a back zipper, reaching overhead, and carrying heavy bags [7]. A systematic review suggested that at least $150^{\circ}$ elbow flexion and $130^{\circ}$ shoulder flexion and abduction are required to perform personal care, eating, and drinking [8]. However, many breast cancer patients are unable to achieve $150^{\circ}$ elbow flexion and $130^{\circ}$ of shoulder flexion even after several years post-surgery [9,10]. Additionally, shoulder morbidities, including pain, loss of strength, and limited shoulder ROM, lead to a declining quality of life in breast cancer patients after surgery $[3,11]$. Consequently, only $59 \%$ of breast cancer survivors returned to work, and even among those who returned to their workplace, a substantial percentage of them were not able to work full time because of physical conditions, including these shoulder problems [12]. Therefore, rehabilitation after breast cancer surgery is essential to improve patients' quality of life and increase the return to work rate.

Breast cancer patients experience the most frequent and significant shoulder morbidities immediately after surgery. Although studies have reported the long-term consequences of breast cancer surgery in the upper body, shoulder ROM and strength during the early phase of rehabilitation have not been studied. More importantly, variances in shoulder ROM and strength according to the types of surgery are not yet fully understood.

Therefore, the purpose of the current study is to examine the shoulder ROM and strength in both the affected and unaffected arm after breast cancer surgery for up to 4 weeks.

\section{Materials and Methods}

\subsection{Participants}

Thirty-two breast cancer patients were recruited from Severance Hospital, Yonsei University Health System, Seoul, Korea, from 14 February to 2 November 2019. Eligibility criteria included the following: (1) age between 19 and 70 years; (2) histologically confirmed stage <IV breast cancer; (3) ability to understand and provide written informed consent in Korean. We excluded (1) patients who were scheduled bilateral breast surgery, (2) breast reconstruction surgery, or (3) existing evidence of recurrent or metastatic diseases. This study was approved by the Institutional Review Board of Severance Hospital (IRB No. 4-2018-1094), and all participants provided written informed consent.

\subsection{Study Designs}

This study was a prospective observational study. Eligible participants were evaluated for all assessment variables five times over the span of a month (day before surgery, hospital discharge (postoperative day 1, POD1), first outpatient visit (POD7-10), second outpatient visit (POD14-20), and third outpatient visit (POD21-30).

\subsection{Outcome Measures}

All measurements were performed in duplicate by a single investigator, on both the affected and unaffected upper limbs. If the difference between the first and second measurements was $>5 \%$, a third measurement was performed, and the closest two values were averaged. 


\subsubsection{Range of Motion}

In each participant, three shoulder movements (flexion, abduction, and extension) of passive range of motion were measured using a digital goniometer (Goniometer bending iron 29-5900, Pakistan). Flexion and abduction were evaluated in the supine position and extension was measured in standing position [13].

\subsubsection{Shoulder Strength}

The shoulder muscle strength, measured in pounds (lb), was determined using a handheld dynamometer (J-tech Medical Industries Inc., Heber City, UT, USA). Strength peak muscle force was measured using maximal voluntary isometric contraction (MVIC) in flexion, abduction, extension [14].

\subsubsection{Shoulder Function Score}

Shoulder function score was calculated for ease of interpretation of shoulder ROM and strength. It was converted to 100 scales for each measurement relative to the baseline and each assessment summed ROM (flexion+ extension+ abduction) and strength value (flexion+ extension+ abduction) was converted to a standard 100-point scale.

\subsection{Statistical Analysis}

We analyzed the entire data using a parametric method after testing for the normality of distribution using the Shapiro-Wilk test. Descriptive analyses were used to evaluate demographic information, baseline body composition, and medical information. Changes in shoulder ROM, strength, and shoulder function score were assessed for both the affected and unaffected sides using univariate repeated measures of ANOVA (RM-ANOVA). When the difference was statistically significant, we conducted a post-hoc comparison between the baseline evaluation and each measurement point. The post-hoc test was performed using the paired $t$-test with Bonferroni's correction [15]. After baseline value adjustment, analysis of covariance was used to compare differences between the affected and unaffected arms. RM-ANOVA was conducted to investigate the pattern of changes according to the surgical type in shoulder ROM, strength, and shoulder function score over time and groups. All statistical analyses were performed using SPSS version 25 software (IBM Corp., Armonk, NY, USA), and statistical significance was at $p<0.05$.

\section{Results}

\subsection{Participants' Characteristics}

Thirty-two patients (15 total mastectomy (TM), 17 partial mastectomy (PM)) diagnosed with breast cancer stage 0-3 participated in this study. The mean age of participants was $52.3 \pm 7.6$ years, and the mean body mass index was $24.6 \pm 2.9 \mathrm{~kg} / \mathrm{m}^{2}$. Of the participants, $46.9 \%$ underwent neoadjuvant chemotherapy (Table 1).

\subsection{Change in Shoulder Range of Motion (from Pre-Surgery to 4-Week Post-Surgery)}

The ROM of flexion and extension on the affected side was significantly reduced immediately after surgery. Although the ROM slowly improved, it remained considerably below baseline levels (flexion $-36.1 \%$ to $-18.2 \%$, extension $-27.2 \%$ to $-16 \%$ ). Notably, the ROM of shoulder abduction significantly decreased immediately after surgery $(-46.7 \%$ at POD1) and barely recovered until the third outpatient visit $(-45.7 \%$ at POD24) to the baseline level (Table 2). In the unaffected side, the only significant difference in ROM occurred in flexion and abduction on POD1, compared with the baseline ROM. After surgery, the ROM between the affected and unaffected arms exhibited a significant difference at all measurement points (Table 2). 
Table 1. Participants' characteristics.

\begin{tabular}{|c|c|c|c|c|c|}
\hline Variable $(N=32)$ & $\begin{array}{c}\text { TM\&ALND } \\
(N=7)\end{array}$ & $\begin{array}{c}\text { TM\&SLNB } \\
(N=8)\end{array}$ & $\begin{array}{c}\text { PM\&ALND } \\
(N=8)\end{array}$ & $\begin{array}{c}\text { PM\&SLNB } \\
(N=9)\end{array}$ & $P$ \\
\hline Age (years) & $50.0 \pm 11.1$ & $53.6 \pm 6.7$ & $52.6 \pm 7.9$ & $52.8 \pm 5.3$ & 0.8 \\
\hline Weight (kg) & $61.7 \pm 8.3$ & $66.5 \pm 9.7$ & $63.0 \pm 7.9$ & $58.4 \pm 6.3$ & 0.3 \\
\hline BMI $\left(\mathrm{kg} / \mathrm{m}^{2}\right)$ & $23.3 \pm 2.4$ & $25.9 \pm 3.7$ & $25.5 \pm 2.9$ & $23.7 \pm 1.9$ & 0.2 \\
\hline Muscle mass (kg) & $23.0 \pm 2.3$ & $23.6 \pm 2.7$ & $22.4 \pm 2.3$ & $20.8 \pm 2.1$ & 0.1 \\
\hline Fat $(\%)$ & $30.1 \pm 4.6$ & $33.5 \pm 5.5$ & $33.0 \pm 6.0$ & $33.6 \pm 6.6$ & 0.6 \\
\hline \multicolumn{6}{|l|}{ Stage $(n, \%)$} \\
\hline 0 & 0 & $3(37.5 \%)$ & $2(25 \%)$ & $4(44.4 \%)$ & \multirow{4}{*}{0.6} \\
\hline 1 & $1(14.3 \%)$ & $3(37.5 \%)$ & $2(25 \%)$ & $5(55.6 \%)$ & \\
\hline 2 & $3(42.9 \%)$ & $2(25 \%)$ & $3(37.5 \%)$ & 0 & \\
\hline 3 & $3(42.9 \%)$ & 0 & $1(12.5 \%)$ & 0 & \\
\hline \multicolumn{6}{|l|}{ Surgery site (n, \%) } \\
\hline Right & $5(71.4 \%)$ & $4(50 \%)$ & $4(50 \%)$ & $6(66.7 \%)$ & 0.8 \\
\hline Dominant arm & $5(71.4 \%)$ & $5(62.5 \%)$ & $4(50 \%)$ & $6(66.7 \%)$ & 0.8 \\
\hline Dissected LNs & $18(9-25)$ & $7(3-13)$ & $17.5(10-26)$ & $9(5-12)$ & $<0.001$ \\
\hline \multicolumn{6}{|c|}{ Surgery duration (min) } \\
\hline & $108.9 \pm 21.4$ & $95 \pm 16.1$ & $122.3 \pm 59.4$ & $93.4 \pm 40.0$ & 0.5 \\
\hline \multicolumn{6}{|c|}{ Drainage removal day $(\mathrm{n}, \%)$} \\
\hline $\begin{array}{l}\text { 1st outpatient visit } \\
\text { (POD 10) }\end{array}$ & $1(14.3 \%)$ & $1(12.5 \%)$ & 0 & $3(33.3 \%)$ & \multirow{4}{*}{0.3} \\
\hline $\begin{array}{l}\text { 2nd outpatient } \\
\text { visit (POD 17) }\end{array}$ & $6(85.7 \%)$ & $4(50 \%)$ & $4(50 \%)$ & $4(44.4 \%)$ & \\
\hline $\begin{array}{l}\text { 3rd outpatient visit } \\
\text { (POD 24) }\end{array}$ & 0 & $3(37.5 \%)$ & $3(37.5 \%)$ & $1(11.1 \%)$ & \\
\hline 4th outpatient visit & 0 & 0 & $1(12.5 \%)$ & $1(11.1 \%)$ & \\
\hline \multicolumn{6}{|c|}{ Neoadjuvant chemotherapy } \\
\hline Yes & $6(85.7 \%)$ & $1(12.5 \%)$ & $7(87.5 \%)$ & $1(11.1 \%)$ & $<0.001$ \\
\hline
\end{tabular}

Values are presented as Mean \pm SD or $\mathrm{n}(\%)$, Dissected LNs are showed median (minimum to maximum range). Abbreviation: Total mastectomy with axillary lymph node dissection; TM with ALND, Total mastectomy with sentinel node biopsy; TM with SLNB, Partial mastectomy with axillary node dissection; PM with ALND, Partial mastectomy with sentinel node biopsy; PM with SLNB, Lymph Nodes; LNs, Postoperative Date; POD.

When ROM was examined according to the surgical types, the greatest reduction in the affected side occurred in patients who underwent TM with axillary lymph node dissection (ALND) (flexion $-48.8 \%$ to $-23.5 \%$, abduction $-61.1 \%$ to $-51.2 \%$ ). The smallest reduction was observed in those who underwent PM with SLNB (PM\&SLNB; flexion $-19.9 \%$ to $-8.1 \%$, abduction $-29.5 \%$ to $-27.2 \%$ ). However, no significant difference existed among the groups and time effects (Figure 1).

\subsection{Change in Shoulder Strength (from Pre-Surgery to 4-Week Post-Surgery)}

Shoulder strength of the affected side was significantly reduced immediately after surgery (reduction rate relative to baseline: flexion $-50.6 \%$, extension $-44.8 \%$, abduction $-49.1 \%$, horizontal adduction $-41.3 \%$, and horizontal abduction $-36.8 \%$ ) and slowly recovered in the 24 days after surgery. In contrast, shoulder strength of the unaffected side gradually decreased over time. Except for shoulder extension on POD10, significant differences between the affected and unaffected arms were observed at all measurement points after surgery (Table 3). A similar pattern of reduction was observed in the shoulder strength of the affected side regardless of the surgical methods (Figure 2). 
Table 2. Change of shoulder range of motion (pre-surgery to 4 weeks post-surgery).

\begin{tabular}{|c|c|c|c|c|c|c|c|c|c|c|}
\hline & Baseline & POD 1 & POD 10 & POD 17 & POD 24 & $P^{\#}$ & $\begin{array}{l}\text { Pbaseline } \\
\text { vs. POD1 }\end{array}$ & $\begin{array}{c}\text { P POD1 } \\
\text { vs. POD10 }\end{array}$ & $\begin{array}{l}\text { P POD10 } \\
\text { vs. POD17 }\end{array}$ & $\begin{array}{l}\text { Ps. POD17 } \\
\text { Ps. POD24 }\end{array}$ \\
\hline \multicolumn{11}{|l|}{ Shoulder range of motion } \\
\hline \multicolumn{11}{|l|}{ Flexion } \\
\hline \multicolumn{11}{|l|}{ Abduction } \\
\hline $\begin{array}{l}\text { Affected side }(\mathrm{n}=30) \\
\text { Unaffected side }(\mathrm{n}=31)\end{array}$ & $\begin{array}{l}169.1 \pm 2.8 \\
170.2 \pm 1.9\end{array}$ & $\begin{array}{l}90.2 \pm 7.1^{* *}+ \\
153.7 \pm 4.4^{*}\end{array}$ & $\begin{array}{c}84.1 \pm 4.5^{* *}+ \\
166.0 \pm 2.4\end{array}$ & $\begin{array}{c}87.9 \pm 5.7^{* *}+ \\
169.0 \pm 2.1\end{array}$ & $\begin{array}{c}91.8 \pm 6.1^{* *}+ \\
171.2 \pm 2.1\end{array}$ & $\begin{array}{c}<0.001 \\
0.004\end{array}$ & $\begin{array}{c}<0.001 \\
0.001\end{array}$ & $\begin{array}{l}0.386 \\
0.0 .21\end{array}$ & $\begin{array}{l}0.437 \\
0.197\end{array}$ & $\begin{array}{c}0.164 \\
0.05\end{array}$ \\
\hline $\begin{array}{l}\text { Affected side }(\mathrm{n}=30) \\
\text { Unaffected side }(\mathrm{n}=31)\end{array}$ & $\begin{array}{l}47.4 \pm 1.1 \\
46.0 \pm 1.2\end{array}$ & $\begin{array}{c}34.5 \pm 2.1^{* *}+ \\
44.7 \pm 1.8\end{array}$ & $\begin{array}{c}37.3 \pm 1.6^{* *}+ \\
44.1 \pm 1.5\end{array}$ & $\begin{array}{c}38.1 \pm 1.8^{* *}+ \\
43.8 \pm 1.6\end{array}$ & $\begin{array}{c}39.8 \pm 1.6^{* *}+{ }^{3} \\
45.8 \pm 1.2\end{array}$ & $\begin{array}{l}<0.001 \\
0.36\end{array}$ & $\begin{array}{c}<0.001 \\
0.568\end{array}$ & $\begin{array}{l}0.200 \\
0.788\end{array}$ & $\begin{array}{l}0.642 \\
0.859\end{array}$ & $\begin{array}{l}0.101 \\
0.133\end{array}$ \\
\hline
\end{tabular}

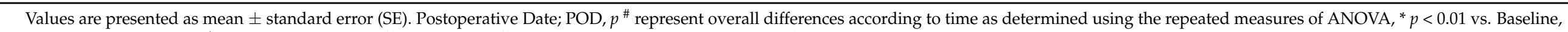
${ }^{* *} p<0.001$ vs. Baseline, ${ }^{+} p<0.01$ between the affected and unaffected side (POD1 to POD 24 adjusted for Baseline value). 
Table 3. Change of shoulder strength (pre-surgery to 4 weeks post-surgery).

\begin{tabular}{|c|c|c|c|c|c|c|c|c|c|c|}
\hline & Baseline & POD 1 & POD 10 & POD 17 & POD 24 & $P^{\#}$ & $\begin{array}{l}P^{\text {baseline }} \\
\text { vs. POD1 }\end{array}$ & $\begin{array}{c}P P O D 1 \\
\text { vs. } P O D 10\end{array}$ & $\begin{array}{c}P \text { POD10 } \\
\text { vs. POD17 }\end{array}$ & $\begin{array}{c}P \text { POD17 } \\
\text { vs. POD24 }\end{array}$ \\
\hline \multicolumn{11}{|l|}{ Shoulder strength } \\
\hline \multicolumn{11}{|l|}{ Flexion } \\
\hline Affected side $(\mathrm{n}=31)$ & $16.0 \pm 0.9$ & $7.9 \pm 0.8^{* *}+$ & $7.8 \pm 0.7^{* *}+$ & $8.8 \pm 0.7^{* *}+$ & $8.9 \pm 0.6^{* *}+$ & $<0.001$ & $<0.001$ & 0.890 & 0.017 & 0.850 \\
\hline Unaffected side $(n=31)$ & $15.5 \pm 0.8$ & $12.7 \pm 0.9^{* *}$ & $11.8 \pm 0.8^{* *}$ & $11.7 \pm 0.6^{* *}$ & $11.0 \pm 0.5^{* *}$ & $<0.001$ & $<0.001$ & 0.173 & 0.866 & 0.071 \\
\hline \multicolumn{11}{|l|}{ Abduction } \\
\hline Unaffected side $(n=31)$ & $15.0 \pm 0.9$ & $12.1 \pm 0.9^{* *}$ & $11.2 \pm 0.7^{* *}$ & $11.1 \pm 0.6^{* *}$ & $11.0 \pm 0.6^{* *}$ & $<0.001$ & $<0.001$ & 0.181 & 0.823 & 0.607 \\
\hline \multicolumn{11}{|l|}{ Extension } \\
\hline Affected side $(\mathrm{n}=31)$ & $22.3 \pm 1.0$ & $12.3 \pm 1.0^{* *}+$ & $15.1 \pm 1.0^{* *}$ & $15.5 \pm 0.8^{* *}+$ & $16.1 \pm 0.7^{* *}+$ & $<0.001$ & $<0.001$ & 0.001 & 0.426 & 0.521 \\
\hline Unaffected side $(n=31)$ & $22.7 \pm 1.2$ & $17.6 \pm 1.1^{* *}$ & $17.4 \pm 1.0^{* *}$ & $19.0 \pm 0.9^{* *}$ & $18.0 \pm 0.8^{* *}$ & $<0.001$ & $<0.001$ & 0.783 & 0.047 & 0.147 \\
\hline \multicolumn{11}{|l|}{ Horizontal adduction } \\
\hline Affected side $(\mathrm{n}=31)$ & $19.6 \pm 1.0$ & $11.5 \pm 1.1^{* *}+$ & $11.3 \pm 1.0^{* *}+$ & $12.3 \pm 0.9^{* *}+$ & $12.9 \pm 1.0^{* *}+$ & $<0.001$ & $<0.001$ & 0.754 & 0.073 & 0.355 \\
\hline Unaffected side $(n=31)$ & $19.5 \pm 1.1$ & $16.4 \pm 1.0$ ** & $16.7 \pm 1.2 *$ & $16.7 \pm 0.9 *$ & $15.3 \pm 0.8^{* *}$ & $<0.001$ & $<0.001$ & 0.649 & 0.979 & 0.006 \\
\hline Affected side $(\mathrm{n}=30)$ & $19.3 \pm 1.2$ & $12.2 \pm 1.1^{* *}+$ & $11.5 \pm 1.0^{* *}+$ & $12.7 \pm 0.8^{* *}+$ & $12.0 \pm 0.8^{* *}+$ & $<0.001$ & $<0.001$ & 0.312 & 0.066 & 0.263 \\
\hline Unaffected side $(\mathrm{n}=31)$ & $19.2 \pm 1.0$ & $17.4 \pm 1.1$ & $15.9 \pm 1.2 *$ & $15.6 \pm 0.8^{* *}$ & $14.9 \pm 0.6^{* *}$ & $<0.001$ & 0.020 & 0.025 & 0.771 & 0.095 \\
\hline
\end{tabular}

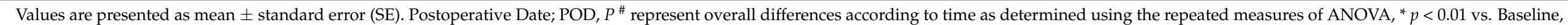

${ }^{* *} p<0.001$ vs. Baseline, ${ }^{+} p<0.01$ between the affected and unaffected side (POD1 to POD 24 adjusted for Baseline value). 

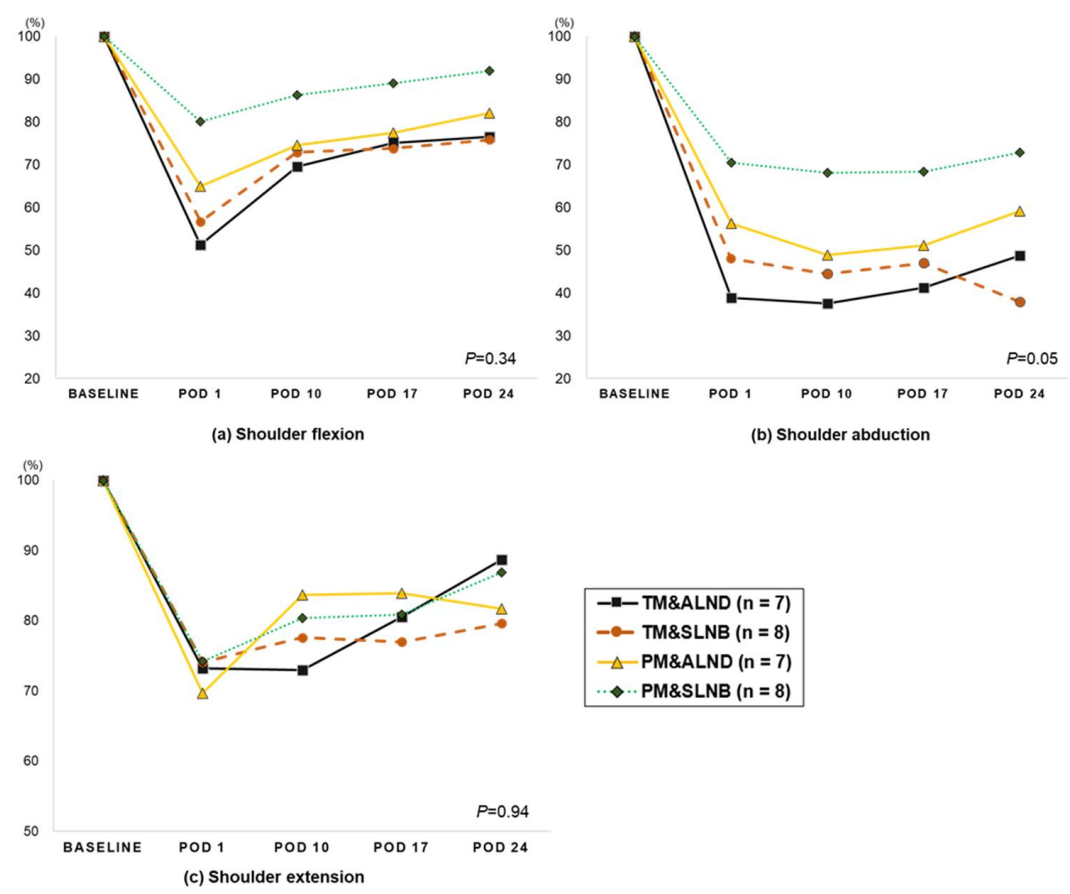

Figure 1. The changes in the shoulder range of motion after breast surgery according to the surgery type in the affected side (descriptive). P: the repeated measure of ANOVA analysis (group time interaction). Abbreviation: Total mastectomy with axillary lymph node dissection; TM\&ALND, Total mastectomy with sentinel node biopsy; TM\&SLNB, Partial mastectomy with axillary node dissection; PM\&ALND, Partial mastectomy with sentinel node biopsy; PM\&SLNB, Postoperative day: POD.

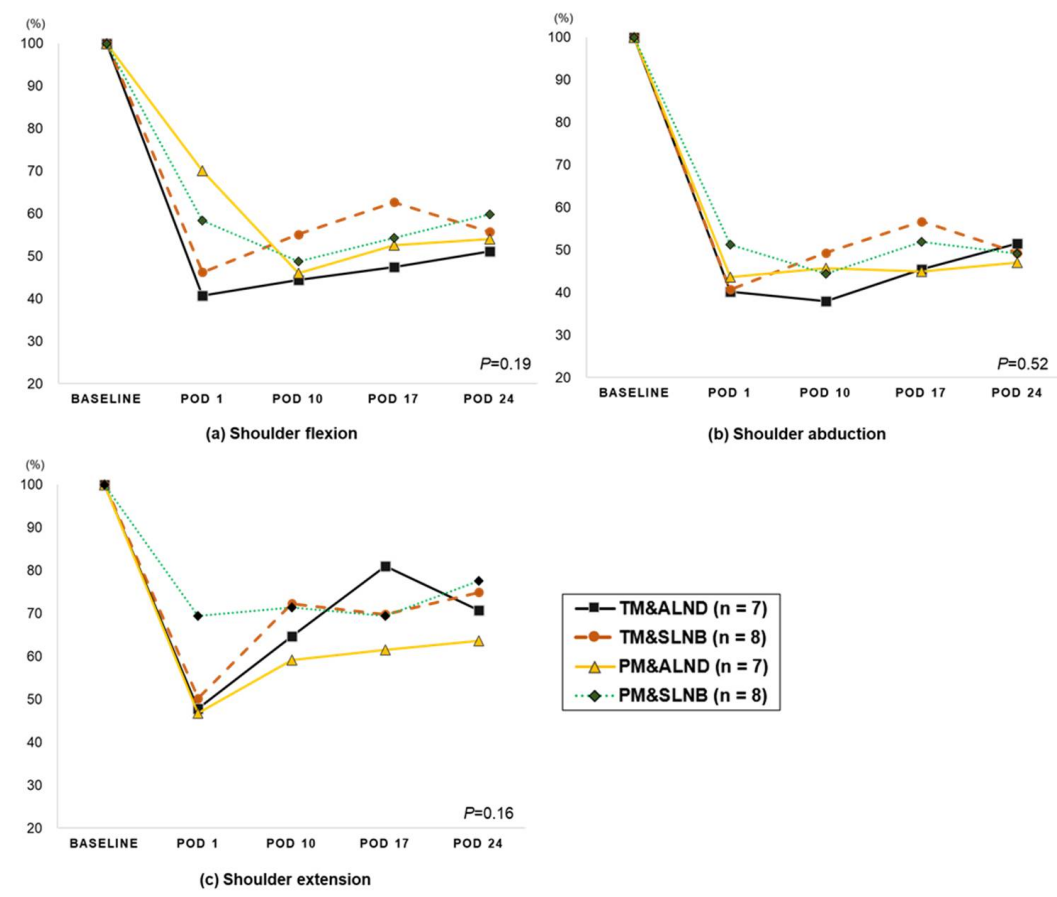

Figure 2. The changes in the shoulder strength after breast surgery according to the surgery type in the affected side (descriptive). $P$ : the repeated measure of ANOVA analysis (group*time interaction). Abbreviation: Total mastectomy with axillary lymph node dissection; TM with ALND, Total mastectomy with sentinel node biopsy; TM c SLNB, Partial mastectomy with axillary node dissection; PM with ALND, Partial mastectomy with sentinel node biopsy; PM with SLNB, Postoperative day: POD. 


\subsection{Change in Shoulder Function (from Pre-Surgery to 4-Week Post-Surgery)}

On the affected arm, both shoulder ROM and strength scores significantly decreased compared to their pre-surgery levels and did not fully recover until 4 weeks after surgery (Table 4). On the unaffected arm, the ROM score only decreased on POD1 compared to its pre-surgery level. Conversely, the shoulder strength of the unaffected arm significantly reduced throughout the study period compared to its pre-surgery level. When shoulder recovery patterns were analyzed by age, body mass index (BMI), and the number of lymph nodes removed, recovery patterns did not differ by BMI and number lymph node recovery: only age (under 55 age vs. over 55 age) showed a difference in the recovery of the ROM score of the affected side ( $P$ for time $=0.04$; Supplementary Figures S1 and S2).

The ROM score showed a different declining pattern on the affected arm according to the surgical method. In terms of strength, a similar pattern of reduction was observed regardless of the surgery method (Figure 3 ).
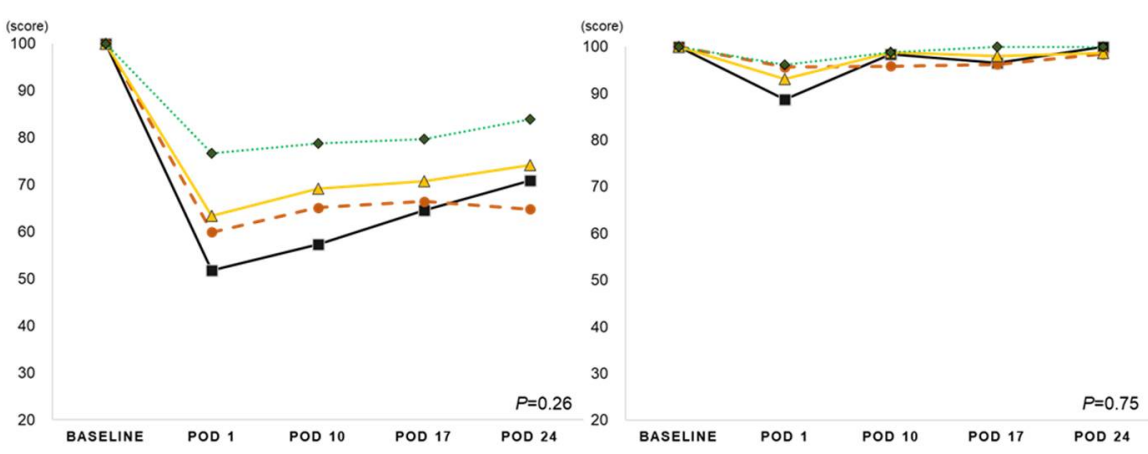

(a-1) Shoulder ROM score in affected side

(a-2) Shoulder ROM score in unaffected side
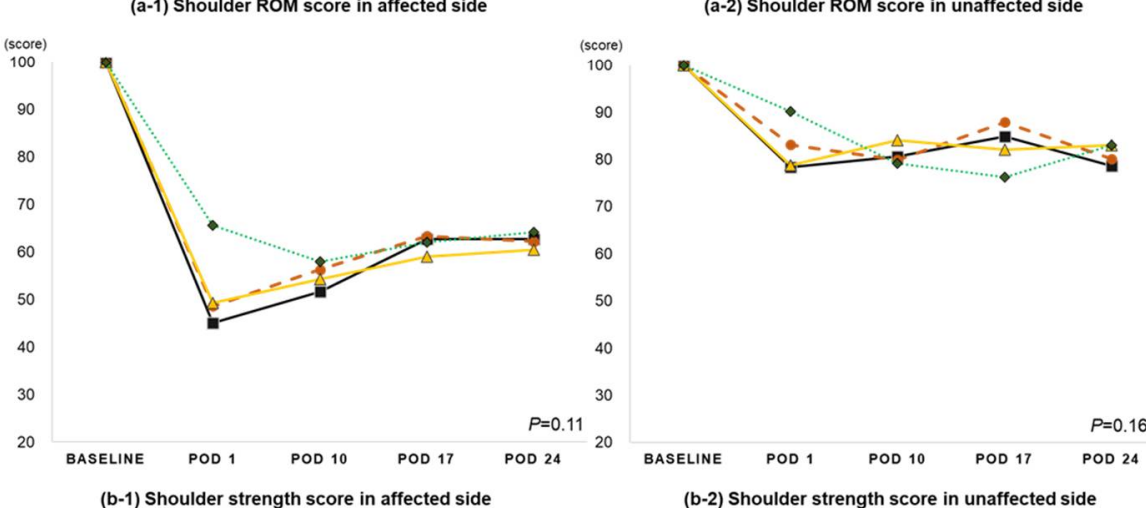

(b-1) Shoulder strength score in affected side

(b-2) Shoulder strength score in unaffected side

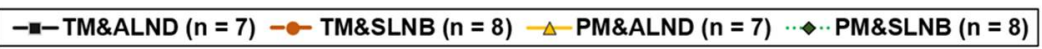

Figure 3. The changes in the shoulder function score in breast cancer patients after surgery according to the surgery type (descriptive). $P$ : the repeated measure of ANOVA analysis (group*time interaction). Abbreviation: Total mastectomy with axillary lymph node dissection; TM with ALND, Total mastectomy with sentinel node biopsy; TM c SLNB, Partial mastectomy with axillary node dissection; PM with ALND, Partial mastectomy with sentinel node biopsy; PM with SLNB, Postoperative day: POD. 
Table 4. Change of shoulder function score (pre-surgery to 4 weeks post-surgery).

\begin{tabular}{|c|c|c|c|c|c|c|c|c|c|c|}
\hline & Baseline & POD 1 & POD 10 & POD 17 & POD 24 & $P^{\#}$ & $\begin{array}{l}P^{\text {baseline }} \\
\text { vs. POD1 }\end{array}$ & $\begin{array}{c}P P^{P O D 1} \\
\text { vs. POD10 }\end{array}$ & $\begin{array}{l}P \text { POD10 } \\
\text { vs. POD17 }\end{array}$ & $\begin{array}{l}P^{P O D 17} \\
\text { vs. POD24 }\end{array}$ \\
\hline \multicolumn{11}{|l|}{ Shoulder function score } \\
\hline \multicolumn{11}{|l|}{ ROM score } \\
\hline $\begin{array}{l}\text { Affected side }(\mathrm{n}=30) \\
\text { Unaffected side }(\mathrm{n}=31)\end{array}$ & $\begin{array}{l}100.0 \pm 0 \\
100.0 \pm 0\end{array}$ & $\begin{array}{c}63.3 \pm 4.0^{* *}+ \\
93.6 \pm 2.4^{*}\end{array}$ & $\begin{array}{c}67.8 \pm 2.4^{* *}+ \\
97.9 \pm 1.4\end{array}$ & $\begin{array}{c}70.5 \pm 2.4^{* *}+ \\
98.5 \pm 1.5\end{array}$ & $\begin{array}{c}73.5 \pm 2.6^{* *}+ \\
100.4 \pm 1.3\end{array}$ & $\begin{array}{l}<0.001 \\
0.018\end{array}$ & $\begin{array}{l}<0.001 \\
0.012\end{array}$ & $\begin{array}{l}0.208 \\
0.072\end{array}$ & $\begin{array}{l}0.146 \\
0.705\end{array}$ & $\begin{array}{l}0.011 \\
0.085\end{array}$ \\
\hline \multicolumn{11}{|l|}{ Strength score } \\
\hline
\end{tabular}

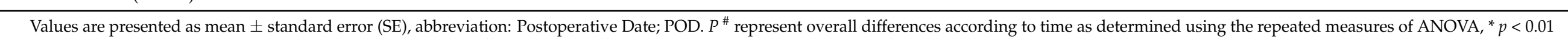
vs. Baseline, ${ }^{* *} p<0.001$ vs. Baseline, $+p<0.01$ between the affected and unaffected side (POD1 to POD 24 adjusted for Baseline value). 


\section{Discussion}

Previous studies have recommended early exercise intervention to alleviate shoulder discomfort and dysfunction related to breast cancer surgery. However, there is insufficient evidence of the extent of the recovery of shoulder ROM and strength during the early recovery phases, such as from immediately after surgery to until 4 weeks. Furthermore, shoulder recovery during the early recovery phase based on different breast cancer surgeries has not been studied. Therefore, we investigated shoulder ROM and strength after breast cancer surgery according to different surgical methods. We found a significant reduction in shoulder ROM immediately after surgery ( $36.7 \%$ reduction compared to baseline), which recovered to up to $73.5 \%$ of the pre-surgery level. A significant reduction in shoulder ROM after 4 weeks was observed in patients regardless of the surgical method; however, patients who underwent TM with ALND seemed to have the most decreased shoulder ROM. Shoulder ROM on the unaffected side was also reduced when measured a day after surgery; however, this phenomenon was not observed 4 weeks after surgery. Similarly, we further noticed that shoulder strength was significantly decreased after surgery $(48.1 \%$ reduction compared to baseline), which recovered only up to $62.5 \%$ at 4 weeks after surgery. The degree of reduction in shoulder strength was similar regardless of the surgical method. Unlike shoulder ROM, a significant decrease in shoulder strength was also observed in the unaffected arm at 4 weeks after surgery (78.9\% compared to baseline).

Within the first month after breast cancer surgery, patients experienced the greatest change in ROM. In this study, we found a $36.7 \%$ reduction in shoulder ROM at POD1, which recovered to up to $73.5 \%$ of the pre-surgery levels at 1 month after surgery. In contrast, the ROM of the unaffected arm was significantly reduced on POD1 and recovered fully by POD10. The significant reduction in shoulder ROM at 1 month after surgery observed in our study agrees with a previously reported study. Springer et al. reported that shoulder ROM recovered to up to about $93 \%$ of baseline. They further observed that participants' shoulder ROM recovered to the pre-surgery level at 1 year after surgery [16]. Cinar et al. [17] reported a significant reduction in shoulder ROM on the fifth day after surgery (treatment group: flexion $74.7 \%$, abduction $64.6 \%$ of baseline; home exercise program group: flexion $60.5 \%$, abduction $53.5 \%$ of baseline), which did not fully recover until 1 month after surgery (treatment group: flexion $95.8 \%$, abduction $93.4 \%$ of baseline; home exercise program group: flexion $76.5 \%$, abduction $69.4 \%$ of baseline). In our study, the ROM of the unaffected arm showed a reduction on POD1, which had almost recovered to the baseline level on POD10.

We further studied whether the recovery of shoulder ROM differs according to the surgical method. As expected, patients who underwent PM with SLNB seemed to recover their shoulder ROM better than those who underwent other methods of surgery, such as TM with ALND. Nesvold et al. [18] reported that impaired shoulder flexion (by $\geq 25^{\circ}$ of the unaffected arm) was observed in $24 \%$ of patients who underwent radical modified mastectomy and $7 \%$ of those who underwent breast-conserving surgery. Compared to breast-conserving surgery, mastectomy significantly increased the risk of impaired shoulder ROM in flexion and abduction by 3.3 (OR 3.3, 95\% CI 1.2-9.14; $p=0.02$ ) and 2.3 (OR 2.3, $95 \%$ CI 1.06-4.98; $p=0.04$ ) times, respectively. Participants who underwent ALND showed a considerable loss of shoulder ROM compared to the SLNB group, even after several years post-surgery $[9,19]$.

There are a few studies which have observed the change in shoulder strength after breast cancer surgery. Belmonte et al. [20] reported significant reduction in shoulder strength in both the affected and unaffected arm 5 years post-surgery. Klassen et al. [21] also observed $12-16 \%$ lower shoulder strength among breast cancer patients during cancer treatments (e.g., surgery, chemotherapy, radiation, etc.). However, both studies observed changes in shoulder strength among breast cancer patients from a few months to a few years after breast cancer surgery, with changes immediately after surgery being absent. In our study, a significant reduction in shoulder strength was found in both the affected and unaffected arms immediately after surgery, which did not recover up to four weeks. 
Interestingly, shoulder strength was significantly reduced in not only the affected arm but also the unaffected arm, although the pattern of decline in shoulder strength differed. The strength of the affected arm decreased immediately after surgery and recovered only up to $52.9 \%$ of the pre-surgery level, while the strength of the unaffected arm gradually declined over 4 weeks.

We noticed that shoulder strength significantly decreased after surgery regardless of the surgical method; these results differ from those of previous studies. Belmonte et al. [20] and Sagen et al. [9] reported that participants who underwent ALND showed a slower recovery of shoulder strength than those who underwent SLNB. The reason why we did not observe differences in our participants' shoulder strength recovery after surgery is unclear. It may be due to the lack of upper body use after surgery or to the relatively short follow-up duration in our participants. We followed up our participants for up to 4 weeks only, whereas other studies followed up their participants' shoulder strength recovery up to several years $[9,19,22]$. If we had performed a longer follow-up of shoulder strength in our participants, we may have observed different shoulder strength recoveries based on the surgical methods.

The reduction in shoulder strength regardless of surgical methods (whether they are more invasive, which may cause more damages in muscles and facia, or less invasive, which may cause only a small or no damage in the muscles and facia) is of interest. In general, upper limb problems, including reduction in shoulder strength after mastectomy or axillary surgery, can cause lymphedema, shoulder restriction, pain, numbness, and weakness [22-24]. In the process of healing, damaged tissue and fascia could become shorter than their lengths before surgery, leading to limitations in shoulder movement $[24,25]$. Additionally, surgery carries the risk of causing nerve injury (involving the intercostobrachial nerve or long thoracic nerve), which can lead to sensation changes or chronic pain in the surgical area [26].

As mentioned above, a gradual reduction in shoulder strength on the unaffected side is an interesting finding. Theoretically, there is no anatomical and physiological reason for this reduction in strength over time. However, breast cancer patients seemed to be discouraged to use their upper body, including both the affected and unaffected sides. Therefore, reduction in shoulder strength could be due to both lack of use and the results of surgery, such as anatomical damage of muscle, facia, and skin. About $70 \%$ of breast cancer patients showed avoidance of strenuous arm activity after surgery, and the primary reasons were pain, scar formation, swelling and considerable fear of lymphedema, misinterpretation of arm care advice, and low coping ability [27]. In addition, patients who avoided using their arms reported more arm and chest symptoms than those who did not avoid using their upper limbs [27]. Patients experiencing pain after surgery may tend to adopt protective postures such as dropped and rounded shoulder and arm, in addition to reduced use of the arm. This results in long-term changes to muscle length and activity [28]. The various physical and psychological effects of surgery can also impede the return to activities of daily living and increase long-term stress [20,29].

This study had some limitations. First, the sample size was small and, therefore, it is difficult to generalize our results. Second, more than $80 \%$ of participants were less than 60 years of age and, therefore, our results may not be generalizable to older breast cancer patients ( $>60$ years). Third, when we measured ROM and strength, participants' shoulder problems before surgery and physical activities after surgery were not controlled. Despite these limitations, we believe that the current study has important clinical implications for understanding the patterns of shoulder function, including shoulder ROM and strength, in the early recovery phase in post-surgery breast cancer patients.

The main finding of this study indicates that shoulder ROM and strength decreased in postoperative breast cancer patients. The reduction in shoulder ROM was observed after surgery, especially so on the affected arm rather than the unaffected arm. The shoulder strength was reduced in both the affected and unaffected sides after surgery. The recovery of ROM showed different patterns depending on the surgical method; however, the strength 
of the shoulder showed a similar pattern of decrease regardless of the surgical methods. The results of this study suggest the need for early rehabilitation after breast cancer surgery.

Supplementary Materials: The following are available online at https:/ /www.mdpi.com/article/10 $.3390 / \mathrm{jcm} 10153416 / \mathrm{s} 1$, Figure S1: The changes in the shoulder ROM score in breast cancer patients after surgery according to subgroup (descriptive), Figure S2: The changes in the shoulder strength score in breast cancer patients after surgery according to subgroup (descriptive).

Author Contributions: Conceptualization, J.M., J.Y.J. and S.I.K.; methodology, J.Y.K., J.J.M., S.I.K. and J.Y.J.; software, J.M.; validation, J.M., J.Y.K. and S.I.K.; formal analysis, J.M.; investigation, J.M., S.Y., J.R. and J.J.M.; resources, J.Y.K., S.P., S.I.K.; writing—original draft preparation, J.M., J.Y.J.; writing - review and editing, J.Y.K., S.P., S.I.K. and J.Y.J.; visualization, J.M.; supervision, J.Y.J. and S.I.K.; funding acquisition, J.M., J.Y.K. and J.Y.J. All authors have read and agreed to the published version of the manuscript.

Funding: This research was supported by the Ministry of Education of the Republic of Korea, the National Research Foundation of Korea (NRF-2020S1A5B5A17090332), Korea Breast Cancer Foundation (KBCF-2020U002) and Yonsei Signature Research Cluster Program of 2021-22-0009.

Institutional Review Board Statement: The study was conducted according to the guidelines of the Declaration of Helsinki, and approved by the Institutional Review Board of Severance Hospital (protocol code 4-2018-1094 and date of approval).

Informed Consent Statement: Informed consent was obtained from all subjects involved in the study.

Data Availability Statement: The data in the current study are available on request from the corresponding author. The data are not publicly available due to the ethical considerations.

Conflicts of Interest: The authors declare no conflict of interest.

\section{References}

1. Loh, S.Y.; Musa, A.N. Methods to improve rehabilitation of patients following breast cancer surgery: A review of systematic reviews. Breast Cancer 2015, 7, 81-98. [CrossRef]

2. Verbelen, H.; Tjalma, W.; Meirte, J.; Gebruers, N. Long-term morbidity after a negative sentinel node in breast cancer patients. Eur. J. Cancer Care 2019, 28, e13077. [CrossRef]

3. Rietman, J.S.; Dijkstra, P.U.; Debreczeni, R.; Geertzen, J.H.B.; Robinson, D.P.H.; De Vries, J. Impairments, disabilities and health related quality of life after treatment for breast cancer: A follow-up study 2.7 years after surgery. Disabil. Rehabil. 2004, 26, 78-84. [CrossRef]

4. Andersen, K.G.; Kehlet, H. Persistent Pain After Breast Cancer Treatment: A Critical Review of Risk Factors and Strategies for Prevention. J. Pain 2011, 12, 725-746. [CrossRef] [PubMed]

5. Lee, T.S.; Kilbreath, S.L.; Refshauge, K.M.; Herbert, R.D.; Beith, J.M. Prognosis of the upper limb following surgery and radiation for breast cancer. Breast Cancer Res. Treat. 2007, 110, 19-37. [CrossRef] [PubMed]

6. Schrenk, P.; Rieger, R.; Shamiyeh, A.; Wayand, W. Morbidity following sentinel lymph node biopsy versus axillary lymph node dissection for patients with breast carcinoma. Cancer 2000, 88, 608-614. [CrossRef]

7. Oosterwijk, A.; Nieuwenhuis, M.; Van Der Schans, C.; Mouton, L. Shoulder and elbow range of motion for the performance of activities of daily living: A systematic review. Physiother. Theory Pract. 2018, 34, 505-528. [CrossRef]

8. Sugden, E.; Rezvani, M.; Harrison, J.; Hughes, L. Shoulder movement after the treatment of early stage breast cancer. Clin. Oncol. 1998, 10, 173-181. [CrossRef]

9. Sagen, A.; Kaaresen, R.; Sandvik, L.; Thune, I.; Risberg, M.A. Upper Limb Physical Function and Adverse Effects After Breast Cancer Surgery: A Prospective 2.5-Year Follow-Up Study and Preoperative Measures. Arch. Phys. Med. Rehabil. 2014, 95, 875-881. [CrossRef] [PubMed]

10. de Oliveira, R.R.; e Silva, M.P.P.; Gurgel, M.S.C.; Pastori-Filho, L.; Sarian, L. Immediate Breast Reconstruction With Transverse Latissimus Dorsi Flap Does Not Affect the Short-term Recovery of Shoulder Range of Motion After Mastectomy. Ann. Plast. Surg. 2010, 64, 402-408. [CrossRef]

11. Kaya, T.; Karatepe, A.G.; Günaydin, R.; Yetiş, H.; Uslu, A. Disability and Health-Related Quality of Life after Breast Cancer Surgery: Relation to Impairments. South. Med. J. 2010, 103, 37-41. [CrossRef]

12. Johnsson, A.; Fornander, T.; Rutqvist, L.-E.; Vaez, M.; Alexanderson, K.; Olsson, M. Predictors of return to work ten months after primary breast cancer surgery. Acta Oncol. 2009, 48, 93-98. [CrossRef]

13. Norkin, C.C.; White, D.J. Measurement of Joint Motion: A Guide to Goniometry; FA Davis: Philadelphia, PA, USA, 2016.

14. Ford-Smith, C.D.; Wyman, J.F.; Elswick, R., Jr; Fernandez, T. Reliability of stationary dynamometer muscle strength testing in community-dwelling older adults. Arch. Phys. Med. Rehabil. 2001, 82, 1128-1132. [CrossRef] [PubMed] 
15. Maxwell, S.E. Pairwise multiple comparisons in repeated measures designs. J. Educ. Stat. 1980, 5, 269-287. [CrossRef]

16. Springer, B.A.; Levy, E.; McGarvey, C.; Pfalzer, L.A.; Stout, N.; Gerber, L.; Soballe, P.W.; Danoff, J. Pre-operative assessment enables early diagnosis and recovery of shoulder function in patients with breast cancer. Breast Cancer Res. Treat. 2010, 120, 135-147. [CrossRef]

17. Cinar, N.; Seckin, Ü.; Keskin, D.; Bodur, H.; Bozkurt, B.; Cengiz, Ö. The Effectiveness of Early Rehabilitation in Patients With Modified Radical Mastectomy. Cancer Nurs. 2008, 31, 160-165. [CrossRef] [PubMed]

18. Nesvold, I.-L.; Dahl, A.A.; Løkkevik, E.; Mengshoel, A.M.; Fosså, S.D. Arm and shoulder morbidity in breast cancer patients after breast-conserving therapy versus mastectomy. Acta Oncol. 2008, 47, 835-842. [CrossRef]

19. Kootstra, J.J.; Dijkstra, P.U.; Rietman, H.; De Vries, J.; Baas, P.; Geertzen, J.H.B.; Hoekstra, H.J.; Hoekstra-Weebers, J.E.H.M. A longitudinal study of shoulder and arm morbidity in breast cancer survivors 7 years after sentinel lymph node biopsy or axillary lymph node dissection. Breast Cancer Res. Treat. 2013, 139, 125-134. [CrossRef]

20. Belmonte, R.; Messaggi-Sartor, M.; Ferrer, M.; Pont, A.; Escalada, F. Prospective study of shoulder strength, shoulder range of motion, and lymphedema in breast cancer patients from pre-surgery to 5 years after ALND or SLNB. Support. Care Cancer 2018, 26, 3277-3287. [CrossRef]

21. Klassen, O.; Schmidt, M.E.; Ulrich, C.M.; Schneeweiss, A.; Potthoff, K.; Steindorf, K.; Wiskemann, J. Muscle strength in breast cancer patients receiving different treatment regimes. J. Cachex. Sarcopenia Muscle 2016, 8, 305-316. [CrossRef]

22. Baron, R.H.; Fey, J.V.; Borgen, P.I.; Stempel, M.M.; Hardick, K.R.; Van Zee, K.J. Eighteen Sensations After Breast Cancer Surgery: A 5-Year Comparison of Sentinel Lymph Node Biopsy and Axillary Lymph Node Dissection. Ann. Surg. Oncol. 2007, 14, 1653-1661. [CrossRef]

23. Schulze, T.; Mucke, J.; Markwardt, J.; Schlag, P.M.; Bembenek, A. Long-term morbidity of patients with early breast cancer after sentinel lymph node biopsy compared to axillary lymph node dissection. J. Surg. Oncol. 2006, 93, 109-119. [CrossRef]

24. Sclafani, L.M.; Baron, R.H. Sentinel Lymph Node Biopsy and Axillary Dissection: Added Morbidity of the Arm, Shoulder and Chest Wall After Mastectomy and Reconstruction. Cancer J. 2008, 14, 216-222. [CrossRef]

25. Lee, C.H.; Chung, S.Y.; Kim, W.Y.; Yang, S.N. Effect of breast cancer surgery on chest tightness and upper limb dysfunction. Medicine 2019, 98, e15524. [CrossRef]

26. Ducic, I.; Zakaria, H.M.; Felder, J.M., 3rd; Fantus, S. Nerve Injuries in Aesthetic Breast Surgery: Systematic Review and Treatment Options. Aesthet. Surg. J. 2014, 34, 841-856. [CrossRef] [PubMed]

27. Lee, T.S.; Kilbreath, S.L.; Sullivan, G.; Refshauge, K.M.; Beith, J.M.; Harris, L.M. Factors That Affect Intention to Avoid Strenuous Arm Activity After Breast Cancer Surgery. Oncol. Nurs. Forum 2009, 36, 454-462. [CrossRef]

28. Shamley, D.R.; Srinanaganathan, R.; Weatherall, R.; Oskrochi, R.; Watson, M.; Ostlere, S.; Sugden, E. Changes in shoulder muscle size and activity following treatment for breast cancer. Breast Cancer Res. Treat. 2007, 106, 19-27. [CrossRef] [PubMed]

29. Kwan, W.; Jackson, J.; Weir, L.M.; Dingee, C.; McGregor, G.; Olivotto, I.A. Chronic Arm Morbidity After Curative Breast Cancer Treatment: Prevalence and Impact on Quality of Life. J. Clin. Oncol. 2002, 20, 4242-4248. [CrossRef] [PubMed] 